\title{
Raising Awareness and Addressing Elder Abuse in the LGBT Community: An Intergenerational Arts Project
}

\author{
CLAIRE ROBSON \\ Simon Fraser University \\ GLORIA GUTMAN \\ Simon Fraser University \\ JEN MARCHBANK \\ Simon Fraser University \\ KELSEY BLAIR \\ Simon Fraser University
}

Abstract

This paper reports on a collaborative digital arts project conducted with LGBT youth and seniors in Vancouver, British Columbia, Canada, funded by the B.C. Council to Reduce Elder Abuse and conducted by faculty members and a doctoral student from Simon Fraser University. In the project, youth and seniors worked together to produce the first Canadian materials on LGBT elder abuse - three digital videos and five informational posters. We report on the methods used to produce and disseminate the materials, and as we reflect on the project's outcomes, we consider both the challenges and potential of digital literacies in this context.

Keywords

elder abuse, queer, intergenerational, digital imagery, arts-based research, youth, elders

\section{Project Overview}

This article reports on an intergenerational, community-based participatory digital arts project, Raising Awareness and Addressing Elder Abuse in the LGBT Community, conducted in British Columbia, Canada and funded by the B.C. Council to Reduce Elder Abuse. In the project, youth and elder participants created videos and poster/fact sheets designed to raise awareness of the issue of elder abuse in the LGBT community.

These digital materials were the first of their kind to be produced in Canada, and were premiered at town hall meetings held in the five regional health authorities of British Columbia. Though we will argue that the production of digital media was appropriate in terms of our pedagogical and social/activist agenda for the project, we will also consider the ethical, educational, and practical challenges we encountered. Links to the videos are provided as part of this report, and the poster/fact sheets are also included, as Figures 1-6, below. 


\section{Project Rationale}

\section{Elder Abuse in the LGBT Community}

Harrison (2006) has suggested that one of the most urgent issues in the LGBT community is gay, lesbian, bisexual, transgendered, and intersex (GLBTI) elder abuse-a situation created by complex and interrelated factors. Firstly, insufficient attention is paid to LGBT older adults generally. They are often described as an invisible population both outside and within the LGBT community (Brotman, Ryan, \& Cormier, 2003; de Vries \& Blando, 2004). This invisibility is multiply determined, and based in stigma and prejudice (LGBT Movement Advancement Project \& SAGE, 2010) as well as concealment (Brotman, Ryan, \& Meyer, 2006; Kochman, 1997; National Senior Citizen’s Law Center, 2011). At the same time, LGBT individuals are at increased risk for elder abuse, neglect, and exploitation, since research shows that they are more likely to live alone, less likely to be partnered, and far less likely to have children (or if they do, to find them supportive). These are all risk factors for elder abuse, neglect, and exploitation (LGBT Movement Advance Project \& SAGE, 2010). In addition, LGBT individuals are more likely to have experienced various forms of trauma and to have abused drugs and alcohol—also known risk factors for elder abuse.

When LGBT individuals do experience abuse, shame and a desire to be seen as normal may make them reluctant to report it, while fear of disclosure and/or homophobia are thought to keep many abused LGBT older adults from seeking help and services. The problem is exacerbated by the fact that elder abuse, along with most aspects of aging, is insufficiently discussed in LGBT public forums or media (Harrison \& Riggs, 2006).

Our aims were twofold:

\section{Project Aims}

1) To raise awareness of elder abuse as it exists in the LGBT community and to address gaps and silences in the public discourse about this topic.

2) To build capacity, agency, and understanding in the LGBT youth and elders who took part in the project and learned and applied skills of script writing, filming, acting, composition, directing, and editing as they worked together to produce the materials.

\section{Digital Imagery: Rationale}

Robson and Blair's ongoing arts practices with the two groups we drew on for this project (both of which are described more fully below) have included art making in many genres, including the written and spoken word, physical performance, three-dimensional art, installations, graphics, and digital video and imagery. Though this range of genres and media was available for the elder abuse project, the choice of digital imagery seemed to be most appropriate.

\section{Appropriateness for Participants}

Digital imagery is generally considered by youth to be an attractive means of communication (Trifonas, 2010, p. 180; Giroux, 2005)—and one that can be counterhegemonic (Williams, 2010, p. 230). Most, if not all, members of Youth for A 
Change (YfAC) communicate with friends and allies regularly via social media platforms such as Facebook, Twitter, Snapchat, and Instagram. For their part, the elders-most of who came of age before computers-have sometimes felt like outsiders in the digital world. They thus welcomed this opportunity to learn and apply new skills in a supportive environment. Davis (2011) has described this kind of work as a productive intergenerational intersection that exploits "a genre of vernacular creativity familiar to younger participants and [provides] the opportunity for an older generation to contribute expertise” (p. 528).

\section{Affinity Spaces}

Queer youth and elders are often seen purely in terms of being frail and at risk (of such things as depression, suicide, isolation, and homelessness). Our project positioned them as producers of social goods, rather than passive consumers (Hayes \& Gee, 2010). In their examination of popular digital culture, Hayes and Gee (2010, p. 186) have argued that important informal learning can occur in virtual "affinity spaces," in which participants work together on problems in order to construct situated understandings as they negotiate meaningful challenges together. This problem-based learning in alternative, nonpedagogical spaces can be viewed as particularly important to our youth and elder participants, many of whom were bullied or otherwise marginalized in their previous learning situations or spent periods of time out of school. Fletcher and Mullett (2016), among others (Koh, 2013), have spoken to the particular effectiveness of digital art making in supporting the engagement and health of youth. As was the case with other digital projects-such as The Framing Safety Project, in which women who have been abused educated others through public displays of photo narratives (Frohmann, 2010) -we hoped to offer an alternative to more traditional notions of language and literacy education. Rather than being about examinable learning through individually generated written text (Hayes \& Gee, 2010, p. 191), this project aimed for the collaborative production of image, video, and text with a significant critical agenda. Instead of being graded or examined, participants traveled across the province to present the materials in real time to health care practitioners and members of the public. Many of them commented on how valuable it was to think on their feet, field questions, and be regarded as teachers and experts.

\section{Ease of Dissemination}

The posters/fact sheets and the videos are free and instantly downloadable from the Simon Fraser University (SFU) Gerontology Research Centre's website. In addition to these digital forms, the printed posters have been distributed as physical artifacts in various communities. These digitally available materials have enjoyed an extended afterlife in terms of their continued online presence and availability —unlike, say, a live theatrical performance, which is by nature ephemeral.

\section{Accessibility and Impact of Materials}

The digital technologies used to make the posters allowed us to create materials that were appropriate for distribution both on and offline. Elder abuse almost always occurs in secret, and (as already noted) is typically underreported. As with many social ills, we tend to distance ourselves from such unpleasant topics-reassuring ourselves that such evils happen to other people and not to us. As the posters are displayed at community 
centres and other public buildings, they have become accessible to people who might never have opened a book or leaflet on the topic, or entered a gallery or theatre to attend a lecture or a play. Even those who might be reluctant to think about the topic can be drawn to take a look at the posters, which are highly visible on the outside windows of local community centres and other public locations.

This kind of narrative and visual representation can be an effective way to convey the nuances and complexity of lived experience (Clandinin \& Connelly, 2000). For instance, in the video made about physical abuse, one partner reminds the other that if she demonstrates her affection publically, it may result in her being denied access to her grandchildren —a neat and effective portrayal of the ways that homophobia can affect intimate relationships.

\section{Approaches to the Project}

\section{Collaborative, Critical Arts Practices for Social Change}

Raising Awareness and Addressing Elder Abuse in the LGBT Community can best be understood as an example of collaborative, critical arts practices for social change (Conrad \& Skinner, 2015; Robson, 2012). This kind of participatory, community based activity seeks to produce social innovation through knowledge translation and knowledge mobilization (Conrad \& Skinner, 2015, p. xv), an intention that is reflected in the project's second aim. The authors argue, with others, that making art with others can also be (though it is not always) a form of critical research (Davies \& Gannon, 2006; Haug, 1992). In this project, for instance, our participants learned about elder abuse in general-including its types, signs and symptoms, and systemic causes-as well as identifying unique ways it might manifest in the lives of LGBT individuals and be fostered by external and internalized homophobia. These understandings and insights have been widely communicated to others through the materials produced.

Theorists in arts engaged research for social change (Butt \& Raymond, 1989; Davies \& Gannon, 2006; Haug, 1992) have argued that critical arts engagements are conducted most effectively in collective collaborations, in which participants can offer each other insights and challenge assumptions in order to arrive at more nuanced understandings. In particular, we hoped that as youth and elders worked together, discussed the issues raised, and negotiated the creative decisions that needed to be made, they might co-create better understandings of how such things as age, frailty, and familial, social, and institutional normativity might impact LGBT relationships.

\section{Intergenerational Focus}

LGBT youth are less likely than other youth to have contact with their parents and grandparents, and LGBT seniors are less likely than other seniors to be supported by their children or grandchildren, if they even have them (LGBT Movement Advance Project \& SAGE, 2010). LGBT youth are also less likely than their heterosexual age peers to meet and interact with older, non-kin LGBT individuals, because of a paucity of LGBT intergenerational meeting places or other events. Though much of what we learn about healthy relationships is communicated through the wisdom, examples, and stories of our elders, LGBT youth are often denied access to these, both in terms of formal and informal education (Boulay, Yeung, Leung, \& Burns, 2014; Cherry-Reid, 2015). Narratives of 
pedophilia continue to imbue intergenerational relationships with fears of perceived impropriety and the risks associated with this - such as perceived or actual accusations and complaints by parents and others. For these reasons, the authors believed that an intergenerational project could have much to offer both youth and elder participants, and that educating the youth about LGBT elder abuse might constitute a small step toward not just raising awareness but also supporting prevention in the younger LGBT population.

\section{Project Design}

The project was designed, managed, and conducted by the four authors of this article, who are all located at SFU. Robson is an adjunct professor in the Department of Gender, Sexuality, and Women's Studies, and founder and co-facilitator of the Queer Imaging \& Riting Kollective for Elders (Quirk-e). Gutman is professor emerita in the Department of Gerontology and an internationally acknowledged expert in the study of elder abuse. Marchbank is a full professor in the Department of Gender, Sexuality, and Women's Studies, and co-facilitator of Youth for A Change (YfAC). Blair is a doctoral student in the Department of English, and co-facilitator of Quirk-e. The digital arts project was facilitated on the ground by Blair and managed by Gutman, who served as principal investigator. Participants in the project were drawn from Quirk-e and YfAC. The project built upon previous artistic collaborations between the LGBT youth and LGBT elders in the two groups.

\section{Participants}

The Queer Imaging \& Riting Kollective for Elders (Quirk-e) is an ongoing, artsengaged collective in the city of Vancouver, British Columbia-composed, at the time of the project, of 20 individuals, all of whom self-identified as old and all but one of whom identified as LGBT and/or queer (one identified as asexual and queer). They were between 60 and 84 years of age. The group meets weekly for two hours during SFU academic semesters, under the direction of Blair and Robson. For the past eleven years, members of the group have made and showcased art in several forms, critiqued each other's work, and shared ideas and resources about topics under investigation. Their work has included public presentations and readings, print anthologies, and videos and visual images — offerings that have regularly drawn the attention of the local community and media. Two members of the group were directly involved in the project-a 77-year-old woman who defines as lesbian and queer, and a 76-year-old woman who defines as trans.

Youth for A Change (YfAC) is an activist/advocacy group in the adjacent city of Surrey, British Columbia, composed of around 12 individuals who meet weekly throughout the calendar year. All members identify as queer, questioning, or ally. At the time of the project, their ages ranged from 13 to 24. The group's activities include the close monitoring of local government agencies (such as the council and school boards) with regard to LGBT rights; education of local organizations such as schools, health care providers, and RCMP; visible presence at queer events, such as gay pride; and, more recently, arts activismincluding theatre, digital imagery, and spoken word. The group is facilitated by Marchbank and her partner, Sylvie Traphan, a trained crisis counselor. Five youth of this group were involved throughout the project. Two identify as queer women; one as a queer youth of colour activist; one as trans; and one as a bisexual activist. Their ages were 16, 18, 19, 19, and 23. 


\section{Community Partners}

Given the first goal of this project (to raise awareness of elder abuse in the LGBT community), its success or failure depended in large part upon the team's ability to disseminate the videos and poster/fact sheets created, and to do so beyond academic circles in order to generate systemic change. We thus created a robust network of local and provincial community partners that would serve to support and promote the project and disseminate its eventual outcomes. These community partners were as follows:

- QMUNITY (a nonprofit LGBTQ/2S organization based in B.C.)

- West End Seniors' Network (a seniors' group)

- Haro Park Centre (a long-term care facility located in the heart of Davie Village-Vancouver's gay enclave)

- Alzheimer's Society of B.C.

- Health Initiative for Men

- Gay and Grey Men’s Group at Vancouver's Roundhouse Community Arts and Recreation Centre

- Quirk-e

- Youth for A Change

- Britannia Community Services Centre (a community centre in GrandviewWoodland, another gay enclave in Vancouver)

- British Columbia's five health authorities: Fraser Health, Interior Health, Northern Health, Vancouver Coastal Health, and Island Health

\section{Project Timeline}

\section{Literature Review and In-Project Education}

In June 2015, the project team conducted a review of current literature about elder abuse in the LGBT community. The team found that little had been written on the topic to that date, and almost no research had been conducted in Canada. This confirmed our hypothesis that the problem of elder abuse in the LGBT community is both underreported and under researched.

In early July 2015, Gutman and Marchbank conducted a half-day training session for the youth and elders in the project and the project's arts facilitator, Kelsey Blair. This training focused primarily on describing and discussing key definitions of elder abuse, the distinction between elder abuse and more generic forms of oppression that occur in the LGBT community, and the distinctions between the various forms of elder abuse as defined in the literature and in professional practice (such as physical, financial, emotional/psychological, sexual, and neglect). This was by no means the end of the education provided to the youth and elders, as conversations continued to occur on a regular basis throughout the development of the materials. Nor was this education entirely onesided, as the youth participants challenged the perceptions of gender and sexuality held by the elders (including members of the research team).

Digital Arts Workshops and Process

After this initial workshop, Blair conducted a series of arts workshops from July to September, 2015, at Britannia Community Services Centre in Vancouver (where the elders 
meet) and at Newton Youth Resource Centre in Surrey (where the youth meet). In terms of pedagogy and practice, these workshops placed a strong emphasis on empowering participants as well as building collaborative skills and structures, which included brainstorming ideas, negotiating consensus, and offering and responding to peer critique. As mentioned earlier, this work built upon existing collaborations between members of the two groups and methods of arts collaboration developed during two earlier projectsnamely, a writing project and a spoken word/theatrical show, developed from the consequent writing and performed in 2016 in several locations (Blair \& Robson, 2016).

Under Blair's facilitation, the youth and elders co-constructed ideas and scenarios for videos and poster/fact sheets on the topic of elder abuse in the LGBT community. As they discussed these various possibilities, they became aware of the various artistic options and choices-and some of their sociopolitical implications. For instance, lesbian experience is often marginalized in research, as the experience of women is either ignored completely or conflated within research conducted with gay men (Lee \& Crawford, 2012). Though violence does exist within lesbian relationships, it is rarely discussed or acknowledged (ristock, 2002). As choices were made about the kinds of images to use in the posters and videos, the participants considered it important to use the videos to draw attention to less well-known situations, such as elder abuse in lesbian relationships, trans experiences in residential care, and intergenerational financial abuse.

\section{Capacity Building Workshops}

As these larger considerations were addressed, Blair also used workshop time and hands-on training and practice to build capacity in the participants with regard to filming, design, editing, acting, and composition. As the project unfolded, more practical elements such as scheduling, budget issues, and complex negotiations of content among community partners and project team members became more challenging, as did the fine balance between the project process and the realities of professional outcomes. The terms of the grant left Blair with a tight timeframe in which to complete this part of the somewhat ambitious project. This time crunch is noted as a project limitation due to some instances of Blair making decisions and completing tasks that she would have preferred to leave to participants. That said, participants did often rise to the challenges they encountered in order to meet and even exceed our expectations; they also learnt something about the stresses involved in social activist projects and how these might be managed, or not.

\section{Review of Materials by Community Partners}

After the videos and poster/fact sheets were designed and constructed, they were sent out to all community partners for feedback and suggestions. The feedback received was reviewed and considered by the elder and youth participants, and much of it was incorporated into the final product. This provided quality control by stakeholders in the field of healthcare and elder care, as well as those in the LGBT population. It also furthered the second aim of the project-that of educating participants about the issue. As questions and objections were raised, the participants were often required to go back to the drawing board and think more deeply about the issues. While this feedback was frustrating for the participants at times, it also challenged and deepened their understandings. For instance, an early suggestion made by one participant to stage and film a lesbian couple being abused on the street by passersby was rejected, as the team leaders reminded them about the 
difference between generic homophobic oppression and elder abuse, which occurs, by definition, within a relationship where there is an expectation of trust.

\section{Project Outcomes}

\section{Materials Produced}

The three digital videos produced by the youth and elders during their arts workshops depicted 1) a female to male (F-M) trans individual in residential care being upbraided for demanding a pap smear, 2) a lesbian couple, one of whom physically and psychologically abuses the other, and 3) a gay male couple where the younger partner makes withdrawals from the older partner's bank account without his knowledge or permission. These digital videos are freely downloadable (https://www.sfu.ca/lgbteol/lgbtelder-abuse-2.html).

Five posters were produced and are included here as Figures 1 through 5 . Three of the posters (Figures 1, 3, \& 4) use images of members of Quirk-e. The poster depicted in Figure 2 uses a community member who was a friend of one of the participants. The poster depicted in Figure 5 uses a stock image. The reasons for these choices are taken up later in this report. Each poster also included (on its reverse side) a definition of the type of abuse highlighted as well as resources available, shown here in Figure 6. They are also downloadable at the link shown above.

Each video offers a contained, stand-alone narrative. They are short (around 3 minutes each) and compelling - thus suitable for both the casual viewer and busy professional. They are also dramatic, as they attach human faces to the more typical analytic, factual, and so-called objective reportage about health or elder issues. (That said, the reverse side of each poster does communicate essential factual information.) 


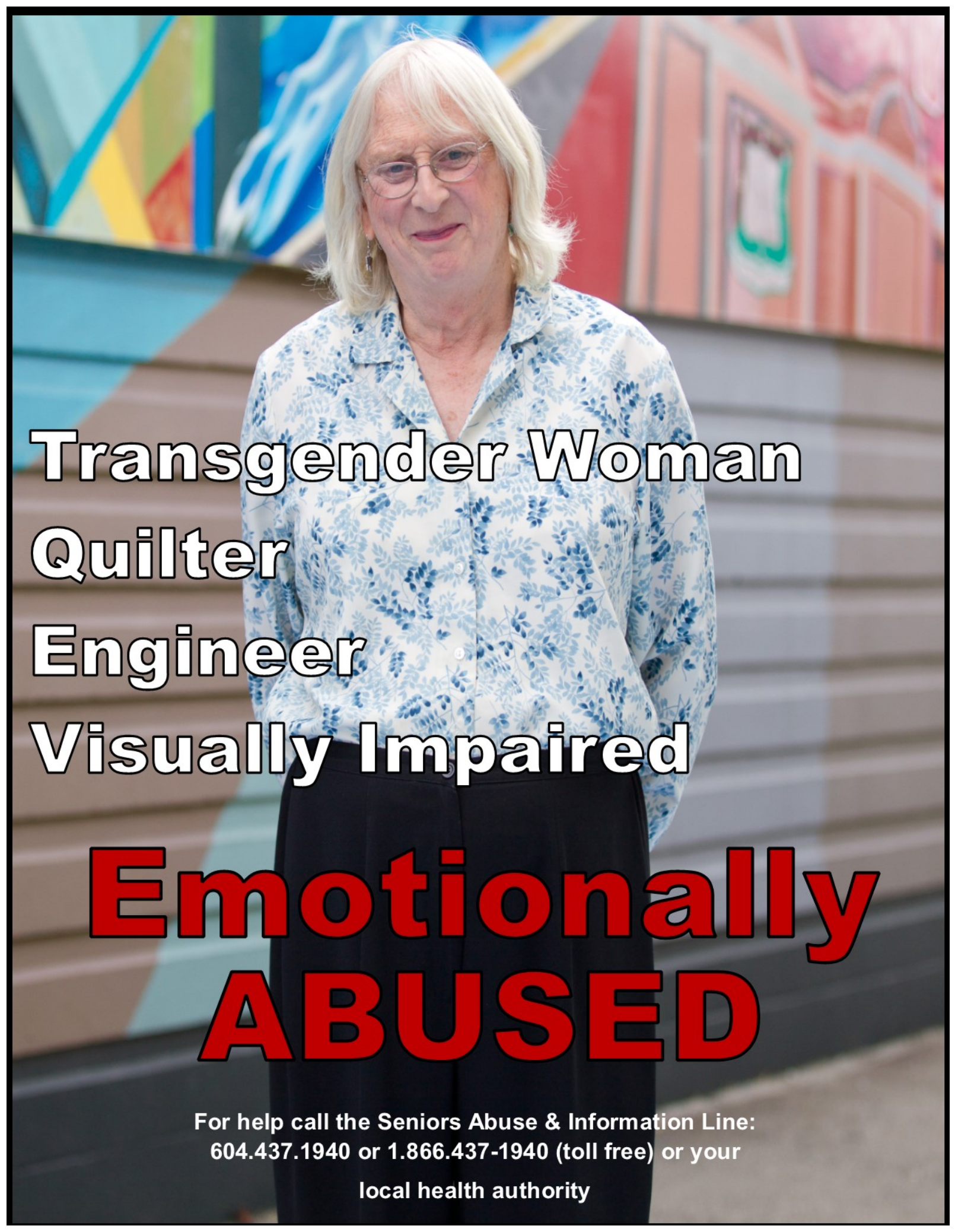

Figure 1. Poster production: Raising Awareness and Addressing Elder Abuse in the LGBT Community project 


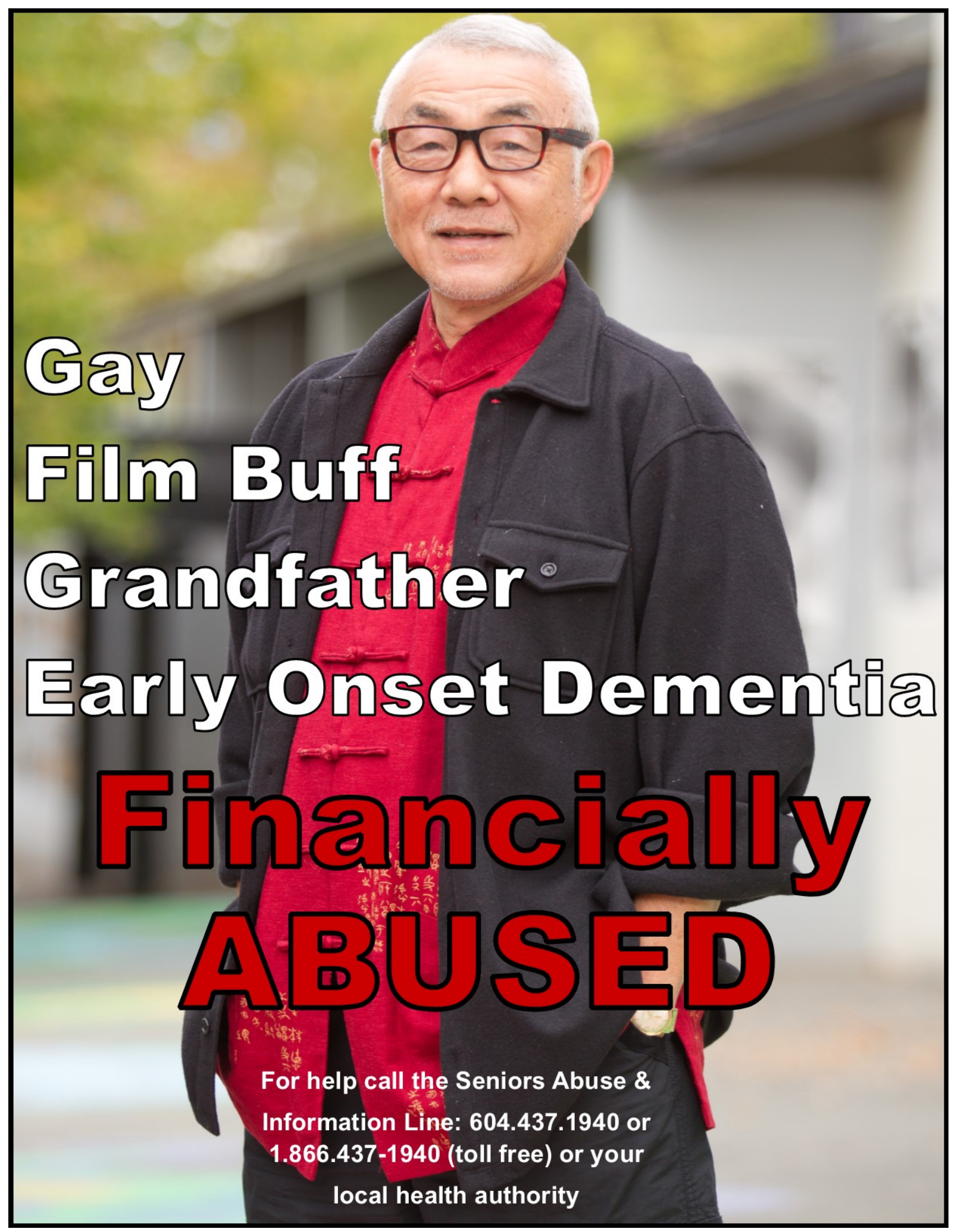

Figure 2. Poster production: Raising Awareness and Addressing Elder Abuse in the LGBT Community project 


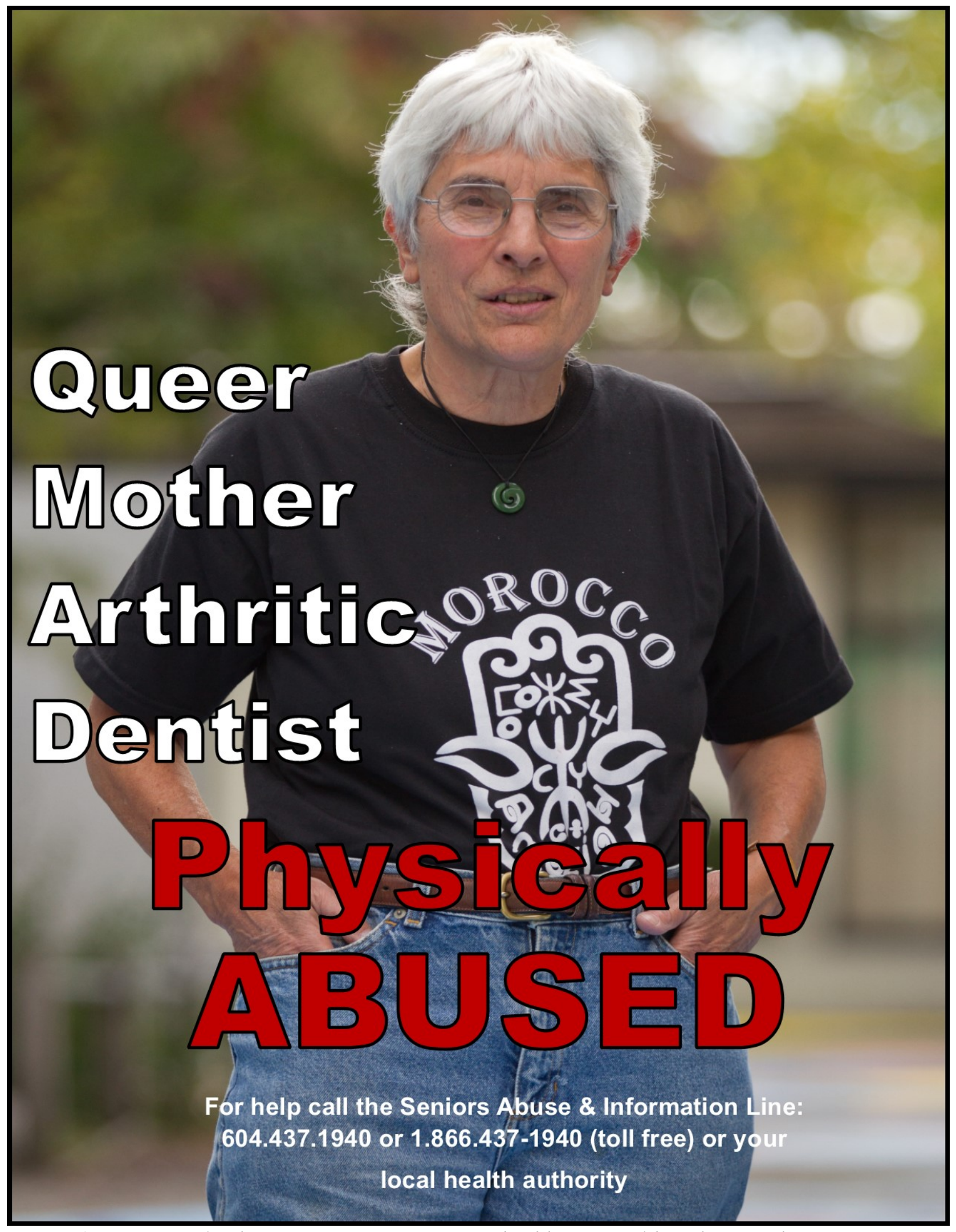

Figure 3. Poster production: Raising Awareness and Addressing Elder Abuse in the LGBT Community project 


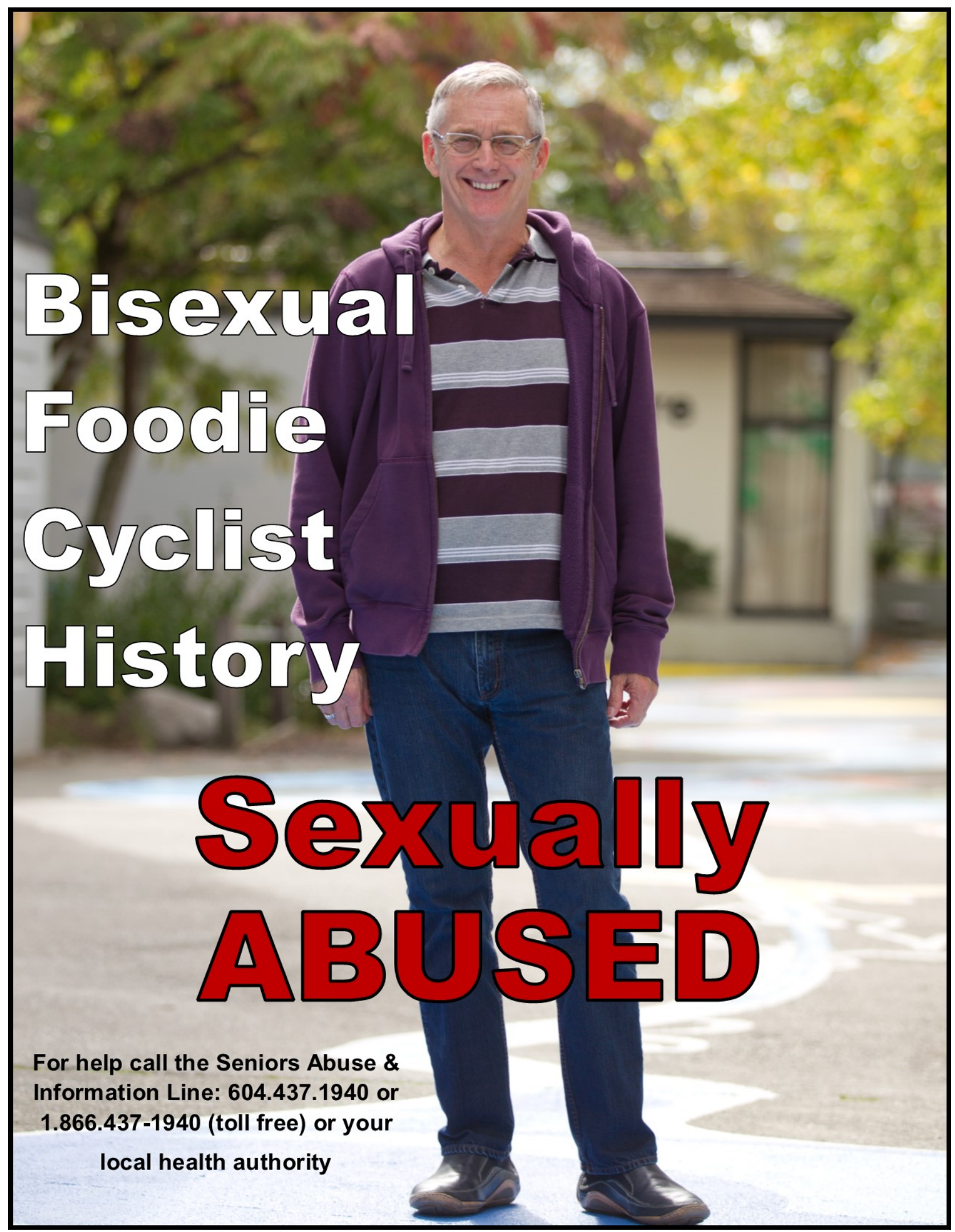

Figure 4. Poster production: Raising Awareness and Addressing Elder Abuse in the LGBT Community project 


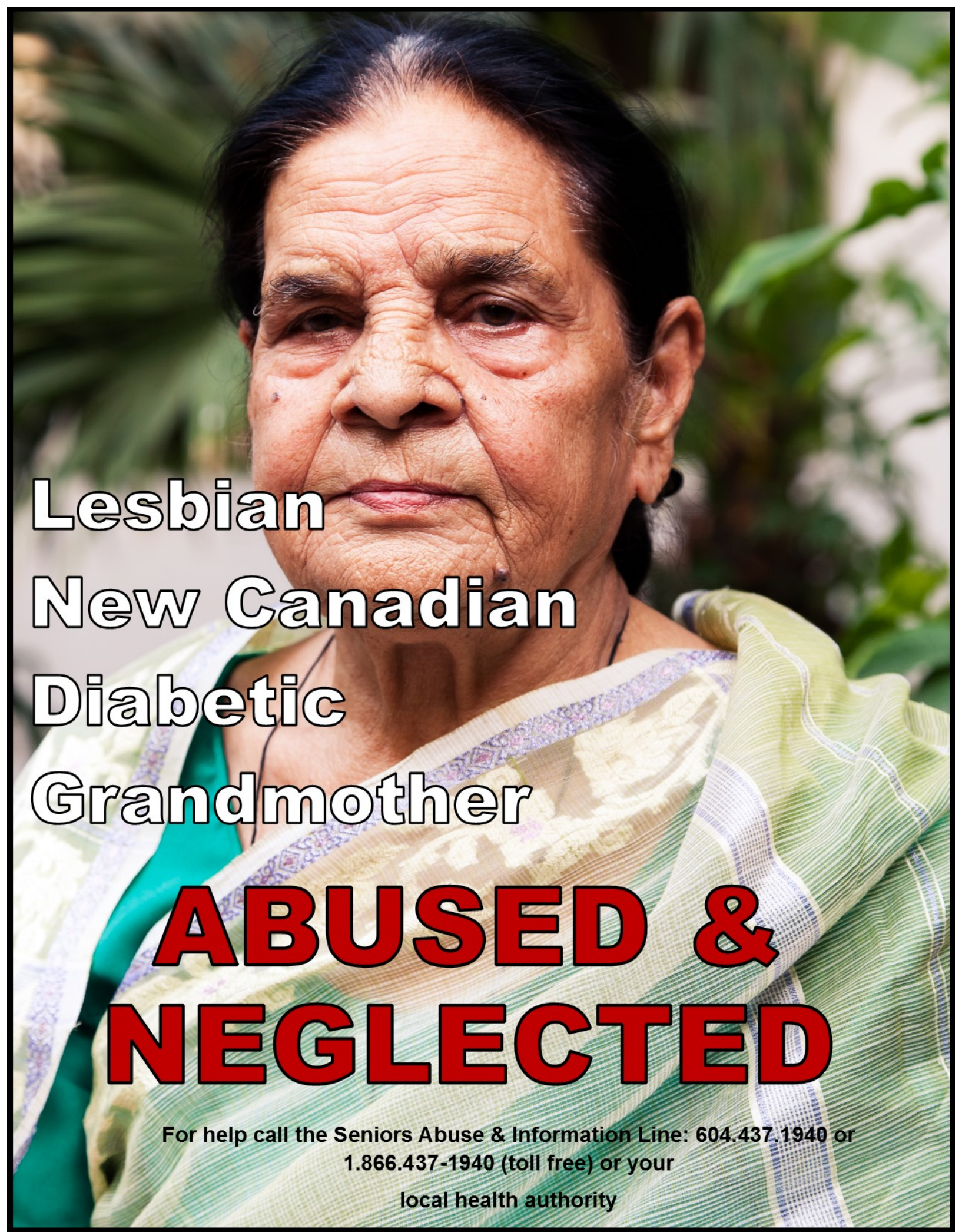

Figure 5. Poster production: Raising Awareness and Addressing Elder Abuse in the LGBT Community project 


\section{LGBTQ Elder Abuse: What Do You know?}

What is Elder Abuse?

Elder abuse occurs when people in positions of trust harm elders, either through their actions or their failure to act.

\section{What is Physical Abuse?}

Actions or behaviors that result in bodily injury, pain, impairment or physical distress. *

\section{Who Commits Elder Abuse?}

- $\quad$ Private households (family, lovers, friends, children, neighbours, caregivers).

- Institutions such as hospitals, care homes, and assisted living (staff, visitors, other residents).

\section{Why are Older LGBTQ People More Vulnerable to Abuse?}

- Stigma and prejudice makes them an "invisible population"

- They are twice as likely to be single, aging alone

- They are less likely to have children or find them supportive

- They are more likely to have experienced trauma and to have had drug and alcohol issues

\section{Why are LGBTQ People Less Likely to Report Abuse?}

- $\quad$ They may not wish to give others even more cause to criticize them.

- They may not be out.

\section{Where to Find Help or Further Information:}

If you are in immediate danger, call 9-1-1.

Seniors Abuse \& Information Line at the BC Centre for Elder Advocacy \& Support: 604.437 .1940 or 1.866.437-1940 (toll free)

Fraser Health: 1-877-732-2808 or visit www.fraserhealth.ca/your_care/adult_abuse_and_neglect/ Interior Health: For direct community numbers visit www.interiorhealth.ca/reportabuse Island Health South Island: 1-888-533-2273; Central Island 1-877-734-4101; North Island 1-866-928-4988 Northern Health: Northern Health Adult Protection Line 1-844-465-7414

Vancouver Coastal Health: ReAct Adult Protection Program 1-877-732-2899

*Abuse Definitions: National Initiative for Care of the Elderly 2015

This fact sheet was produced by the Simon Fraser University Gerontology Research Centre in cooperation with QUIRK-E and Youth for A Change, supported by a grant from the BC Committee to Reduce Elder Abuse (CREA)

Figure 6. The reverse side of each poster. 


\section{Capacity Building}

As noted earlier, both youth and elders had opportunities to learn some of the basics of script writing, editing, concept design, direction, film editing, public speaking, and project management. They learned skills that might serve them in future employment or projects, whether creative, activist, or both. These skills were not confined to making the materials. Participants traveled across B.C. with the research team, spoke to disparate audiences, and answered questions from professionals working in various organizations. For some of the youth, an activity as simple as making small talk at a post-screening reception with the director of a nonprofit or a university academic was a new and unusual opportunity. It also served as an important experience for the health care professionals, many of whom had had no previous opportunities to consider this topic.

Educators suggest that when students teach others, they learn more quickly and more deeply (Gansemer-Topf, 2005). This proved to be the case in this project, as participants thought through some thorny and complicated questions. These questions included the following: What are the key take home messages to be communicated to the general public about elder abuse in the LGBT community? Given the fact that only three videos and five posters/fact sheets will be designed, which of the many populations in the LGBT community should be represented (i.e., lesbian, gay, trans, bisexual, male, female, two-spirited), and in what combinations? How might intersectionality be taken into account, to show the various ways in which LGBT individuals identify other than gender and sexuality—for instance, as grandparents, people with disability, and people of colour? How might the materials properly represent ethnic and racial diversity? And how might the posters and videos avoid portraying those who suffer from abuse purely as victims (thus reinscribing victim narratives)? The thought given to these questions is reflected in the range of images selected in the videos and posters, the nature of these images, and the multiple identifications attached to them (such as quilter, grandmother, diabetic).

\section{Dissemination and Evaluation}

As the materials were being designed, the project team began planning for their dissemination throughout the province of British Columbia. The initial dissemination phase was organized around six town hall meetings, held between February and March, 2016. Vancouver Coastal Health, Fraser Health, Island Health, and Northern Health each hosted one meeting, while two were in Interior Health. Informational flyers about the town halls were also produced and sent to local community partners for distribution. The project budget included sufficient funding for transporting one elder, one youth, and the project team leader to each of the town halls. A page dedicated to the project was also established on the SFU Gerontology Research Centre's website (https://www.sfu.ca/lgbteol/lgbt-elderabuse-2.html).

Exit surveys were conducted at all the town hall meetings, records were kept of attendance at town hall and other meetings, and website traffic is monitored and recorded on an ongoing basis.

At the time of writing, we have recorded the following with regard to uptake of the materials:

- Over 1,400 people have seen the materials at town halls and other presentations. 
- Almost all 2,500 posters have been distributed.

- The "LGBT Elder Abuse" page on the SFU Gerontology Research Centre's LGBT Endof-Life Conversations website has been visited over 900 times, and is the most popular page (after the home page). While a video of one of the town hall meetings has been viewed by 64 people, the Neglect video has been viewed by 262, the Financial Abuse video by 176, and the Emotional \& Physical Abuse video by 201.

- Materials are being routinely used in service provider trainings (e.g., in the City of Surrey, City of Richmond, and at Kwantlen Polytechnic University).

- We have received numerous requests for public screenings and presentations of the materials, such as presentations at gay pride festivals and presentations for many professional groups. These have included presenting to groups working with Chinese speaking communities (held jointly with MOSAIC, an organization serving immigrants and refugees) and with South Asians in Surrey (held jointly with Sher Vancouver, a support group for LGBTQ South Asians). A presentation at the Violence Against Women forum in South West Scotland included staff from the Office of the B.C. Public Guardian and Trustee, the Dumfries and Galloway Council in Scotland, the National Sexual Violence Prevention Project in South West England, the Dumfries and Galloway Police, Scotland's Rural College, and South West England's Rape Crisis and Sexual Abuse Centre, as well as doctors from the Plymouth Institute for Health (UK). Presentations were also made at the Roundhouse Community Arts and Recreation Centre (held jointly with the Vancouver Park Board) and the Égale summit on aging in Toronto.

- All four authors have presented at various academic conferences and will present at the International Federation on Ageing (IFA) Global Conference on Ageing in August, 2018. Though this scholarly work is clearly important, we focus the attention in this report on public presentations that reach diverse populations with little previous knowledge or understanding of the topic.

We would argue that for a relatively short and small project, Raising Awareness and Addressing Elder Abuse in the LGBT Community surpassed our expectations in terms of dissemination.

\section{Other Outcomes}

The tangible outcomes of the project are demonstrated through the strong uptakes recorded in the data offered above. Other outcomes are more difficult to quantify, but this does not make them any less significant (Robson, 2015).

\section{Impact on Participants}

Increased agency and visibility. Both youth and elders are often seen in our North American culture to be at risk, and in need of being done for rather than as capable of doing. As youth and elder participants travelled together to various speaking engagements, they were positioned differently—as leaders, advocates, spokespeople, and even experts.

Improved skills. Participants learned important skills and felt proud of both the materials they produced and in their ability to speak in public about the topic of elder 
abuse in the LGBT community. This was demonstrated at a public presentation of the project in a Vancouver community centre (November, 2016), which featured a panel presentation of both youth and elders speaking fluently and at length. Many members of the audience commented to the project team that they were impressed with how articulate and well informed the participants were; notably, participants had in-depth knowledge of the issues, and were able to answer follow-up questions or position the specifics of the discussion in broad cultural terms. For example, a question about how participants chose the scenarios addressed in the three videos was answered by one of the youth, who spoke about the importance of recognizing the intersectionality of gender, age, and sexuality.

Increased knowledge and understanding. During this project, participants learned about elder abuse; about internal, external, and institutional homophobia and transphobia; and about processes of ageing. The youth, in particular, knew very little going into the project about elder abuse in their communities, and their involvement in this project can be seen as an important investment in the future. All participants also practiced what Berglin (2017) has called the "twenty-first century skills" of purposeful play and creative ideation, in both individual and collective contexts.

Intergenerational opportunities. Youth and elders said that they enjoyed working together and learned a great deal from each other. Though most people would say that it is important for youth to have role models, there are few opportunities for youth and elders to meet in the LGBT community, and even then they are hampered by their expectations and assumptions about each other. A case in point is offered by Gayle, one of the elder participants, and Candy, one of the youth, who play the resident and the caregiver (respectively) in the video about residential care. Gayle presents somewhat conservatively and Candy looks very countercultural. The two would have been unlikely to meet or spend time together under normal circumstances, but developed a close working relationship during this project. This led to more informal conversations about their negotiations of gender identity (Gayle is transsexual and Candy is a gender fluid drag queen).

Impact on the community. It is impossible for us to track the impact of the materials that have been downloaded or distributed. We can only assume that it continues to ripple through the province of B.C., as the videos and posters have been displayed in community centres and other public buildings and passed along by email and other forms of social media. As project leader, Gutman continues to receive queries about the project on a regular basis.

\section{Project Challenges}

\section{Choice of Medium: Digital Imagery}

Though we believe that our choice of digital imagery was sound because of the positive outcomes achieved in the project, it did lead to some challenges. The posters were fairly easy to design, construct, and export, but the videos were more difficult. The common perception is that new technologies such as the iPhone have made artistic practices almost universally accessible. This is true to a large extent, as participants in a broad range of projects have voiced their thoughts and concerns using methods such as 
Photovoice (Wang \& Burris, 1997). In this project, however, the digital outcomes were intended for public screenings and ongoing use by health care and elder care professionals. It was necessary to make them as professional as possible in both look and quality, in terms of production values, content, acting, filming, and editing. A tension in the project developed between process (which our theoretical position and consequent methodology required to be collaborative) and product (which our dissemination plan required to be professional). This challenge was compounded by the limitations of our equipment and our participants' experience. We only had one camera, which meant that we could not cut easily to other angles in the editing process. Our microphone was not professional, and we had no lights or other professional filming equipment. Our participants had little or no training or experience in screenwriting, filming, film editing, or acting.

Though we are proud of our participants' achievements and the materials they made, working with an unskilled team of participants put great demands on Blair's skills as a facilitator and also necessitated some compromises. Our original aim was to have participants complete as much of the work as possible; however, as the project evolved, it became necessary to hire one professional actor and a professional photographer, and also for Blair to complete more of the film editing than she would have liked. In hindsight, we might have allowed more time for building capacity in digital technology and for the design and production of the videos especially. We probably could not have reconfigured our budget, since the cost of upgrading our equipment from amateur to semi-professional would have been prohibitive.

\section{Issues of Representation, Race, and Diversity}

It was difficult to find victims who were willing to speak openly and in public about their experience of abuse, probably because of the shame and fear it produces. One of the striking absences or gaps in the project was the fact that over its entire course, no one ever revealed or reported firsthand accounts of such experiences-something we have found typical in our work with other marginalized populations. Though we used fictional images and videos to humanize the topic, we regret the absence of firsthand accounts.

In choosing the images, we were concerned with not showing victimization (for instance, images of bruised and traumatized people). Following the example set by the public education campaign, Zero Tolerance of Violence against Women and Girls (Hart, 1997), we elected to use images of people who looked either neutral or happy. Unlike the Zero Tolerance campaign, which chose not to show any women of colour until the launch of the fifth poster (to avoid the racist allocation of domestic and sexual violence onto communities of colour), we wanted to integrate them from the beginning, to show that abuse transcends communities. That said, we found this difficult in practice. Though Vancouver and Surrey are ethnically diverse cities and the two participant groups do include South Asian members (as well as Jewish and First Nations), we failed despite considerable efforts to find any South Asian elders willing to model for the posters. This may be due to the reluctance to publicly identify as being both LGBT and abused, in the belief that this represents a double stigma-a hypothesis that would merit further research. The Chinese male depicted in Figure 2 was a friend of one of the participants, and we paid for and used a stock image for Figure 5, which depicts a South Asian woman. Despite this limitation, the poster/factsheets have been translated into Chinese and Punjabi and, as a later part of the project, discussion sessions were held with individuals who provide service 
to elders in these communities (the two largest ethnic subgroups in each city and in the province). We also note our failure to fully represent First Nations or Two-Spirited perspectives.

\section{Conclusion}

Assessing the value of any research can be difficult. This can be particularly true of arts-based research, where the attribution of value or worth to artistic productions is largely subjective, and other outcomes, such as social change or participant agency, are difficult to quantify. These caveats aside, and bearing in mind the limitations noted above, we do believe that the project was successful in many regards. On the first score (the artistic merit of the materials), the materials exceeded our expectations and were well received by the professionals who viewed them. As the first materials of their kind in Canada, they fill a gap in the field, and we were pleased with the uptake in terms of video downloads and requests for posters (which continues at the time of writing).

On the second score - that is, social change and participants' agency — we turn to the three questions asked by McDermott (2010, p. 7) regarding research validity. She suggests that arts researchers might ask themselves: "What purpose does the research serve?" "Whom does it serve?” And, most importantly, "How does it effect change?” Our research and the materials produced reached a wide audience of key stakeholders; in so doing, they have raised awareness of elder abuse in the LGBT community. They also helped change perceptions of LGBT youth and elders, as our participants became highly visible at town halls and other meetings and presentations. The participants said that they enjoyed being involved in the project and were proud of the results; furthermore, they felt that they learned a great deal about the topic, themselves, and each other, as well as some of the basics of writing, composition, filming, directing, and design. By crossing boundaries and building sustainable bridges between academia and the community, the sciences and the arts, and youth and elders, Raising Awareness and Addressing Elder Abuse in the LGBT Community offers a useful and transferable model of arts-based research with a clear critical agenda.

\section{References}

Berglin, J. (2017). An interview with Olivia Gude about connecting school and community arts practice. Arts Education Policy Review, 118(1), 60-66.

Blair, K. \& Robson, C. (2016, July). Queer community performance in Canada across Generations. Paper presented at Q2Q: A Symposium on Queer Theatre \& Performance in Canada. SFU Woodward's Goldcorp Centre for the Arts, Vancouver, BC, Canada.

Boulay, N., Yeung, B., Leung, C., \& Burns, D. P. (2014). LGBTQ role models and curricular controversy in Canada: A student symposium. Paideusis: Journal of the Canadian Philosophy of Education Society, 22(1), 19-27.

Brotman, S., Ryan, B., \& Cormier, R. (2003). The health and social service needs of gay and lesbian elders and their families in Canada. The Gerontologist, 43, 192-202. doi:10.1093/geront/43.2.192

Brotman, S., Ryan, B., \& Meyer, E. (2006). The health and social services needs of gay and lesbian seniors and their families in Canada. Final Report. McGill

University School of Social Work. 
Butt, R., \& Raymond, D. (1989). Studying the nature and development of teachers' knowledge using collaborative autobiography. International Journal of Educational Research, 13(4), 341-466.

Cherry-Reid, K.A. (2015). Singing queer: Archiving and constructing a lineage through song. (Master's thesis). University of British Columbia. Retrieved from https://open.library.ubc.ca/cIRcle/collections/ubctheses/24/items/1.0223045

Clandinin, F. M., \& Connelly, J. (2000). Narrative inquiry: Experience and story in qualitative research. San Francisco, CA: Wiley \& Sons.

Conrad, D., \& Skinner, A. (Eds.). (2015). Creating together: Participatory, communitybased, and collaborative arts practices and scholarship across Canada.

Waterloo, ON: Wilfred Laurier University Press.

Davies, B., \& Gannon, S. (Eds.). (2006). Doing collective biography. Maidenhead, UK: Open University Press.

Davis, D. (2011). Intergenerational digital storytelling: A sustainable community initiative with inner-city residents. Visual Communication, 10(4), 527-540.

de Vries, B., \& Blando, J. (2004). The study of gay and lesbian aging: Lessons for social gerontology. In G. Herdt \& B. de Vries (Eds.), Gay and lesbian aging: Research and future directions (pp. 3-28). New York, NY: Springer.

Fletcher, S., \& Mullett, J. (2016). Digital stories as a tool for health promotion and youth engagement. Canadian Journal of Public Health, 107(2), 183-187.

Frohmann, L. (2010). The framing safety project: Battered women's photo-narratives as public pedagogy. In J. A. Sandlin, B. D. Schultz, \& J. Burdick (Eds.), The handbook of public pedagogy (pp. 341-350). New York, NY: Routledge.

Gansemer-Topf, A. (2005). Learning by teaching others: A qualitative study exploring the benefits of peer teaching. Landscape Journal, 24(2), 198-208.

Giroux, H. (2005). Cultural studies in dark times: Public pedagogy and the challenge of neoliberalism. Fast Capitalism, 1(2). Retrieved from http://www.fastcapitalism.com

Harrison, J. (2006). Coming out ready or not! Gay, lesbian, bisexual transgender and intersex ageing and aged care in Australia: Reflections, contemporary developments and the road ahead. Gay and Lesbian Issues and Psychology Review, 2(2), 44-50.

Harrison, J., \& Riggs, D. W. (2006). Editorial: LGBTI ageing. Gay \& Lesbian Issues and Psychology Review, 2, 4-5.

Hart, S. (1997). Zero tolerance of violence against women. In M. Ang-Lygate, C. Corrin, and M. Henry (Eds.), Desperately seeking sisterhood, still challenging and building (pp. 95-105). Abingdon, UK: Taylor and Francis.

Haug, F. (1992). Beyond female masochism: Memory-work and politics. New York, NY: Verso.

Hayes, E. R., \& Gee., J. P. (2010). Public pedagogy through video games: Design, resources, and affinity spaces. In J. A. Sandlin, B. D. Schultz, \& J. Burdick (Eds.), The handbook of public pedagogy (pp. 185-193). New York, NY: Routledge.

Koh, K. (2013). Adolescents' information-creating behavior embedded in digital media practice using scratch. Journal of the American Society for Information Science and Technology, 64(9), 1826-1841.

Kochman, A. (1997). Gay and lesbian elderly: Historical overview and implications for 
social work practice. In J. K. Quan (Ed.), Social services for senior gay men and lesbians (pp. 1-10). New York, NY: Harrington Park Press.

Lee, I. C., \& Crawford, M. (2012). Lesbians in empirical psychological research: A new perspective for the twenty-first century? Journal of Lesbian Studies, 16(1), 4-16.

LGBT Movement Advancement Project \& SAGE (March 2010). Improving the lives of LGBT older adults. Retrieved from

http://www.lgbtmap.org/policy-and-issue-analysis/improving-the-lives-of-lgbt-olderadults

McDermott, M. (2010). Outlaw arts-based educational research. Journal of Curriculum and Pedagogy, 7, 6-14. doi:10.1080/15505170.2010.10471306

National Senior Citizen's Law Center (2011). LGBT older adults in long-term care facilities: Stories from the field. Retrieved from http://www.lgbtagingcenter.org/resources/pdfs/NSCLC_LGBT_report.pdf

ristock, j. l. (2002). No more secrets: Violence in lesbian relationships. New York, NY: Routledge

Robson, C. (2012). Writing for change. New York, NY: Peter Lang.

Robson, C. (2015, April). It is hard to see the brokenness of those who have learned to blend in: A case study in catalytic validity. Paper presented at the American Educational Research Association 2015 Annual Meeting, Chicago, IL, USA.

Trifonas, P.R. (2010). Digital literacy and public pedagogy: The digital game as a form of learning. In J. A. Sandlin, B. D. Schultz, \& J. Burdick (Eds.), The handbook of public pedagogy (pp. 179-184). New York, NY: Routledge.

Wang, M., \& Burris, M-A. (1997). Photovoice: Concept, methodology, and use for participatory needs assessment. Health Education \& Behavior, 24(3), 369-387.

Williams, L. (2010). Hip-hop as a site of public pedagogy. In J. A. Sandlin, B. D. Schultz \& J. Burdick (Eds.), The handbook of public pedagogy (pp. 221-232). New York, NY: Routledge. 